\title{
“LO NOTAS, LO SIENTES”. RETÓRICAS SOBRE PRÁCTICAS DE DISCRIMINACIÓN RACIAL
}

\author{
"You notice it, you feel it". Rhetorics on racial discrimination practices
}

\author{
Laura Escudero Zabala*
}

\begin{abstract}
Resumen. Identificar e interpretar prácticas de discriminación racial, es un asunto complejo. En el presente se expone un análisis de un trabajo etnográfico con personas migrantes racializadas en el contexto de la ciudad española de Madrid. En concreto se trata de una aproximación a las formas retóricas que las personas tienen para explicar que han experimentado prácticas de discriminación racistas. En ese sentido, más allá de las prácticas espectaculares de discriminación como agresiones u ofensas discursivas, voy a detenerme en aquellos relatos que hablan de prácticas más ambiguas, más encubiertas; para ver cómo construyen subjetivamente aquello que perciben como objetivo.
\end{abstract}

Palabras clave: discriminación racial; incorporación racial; percepción; retóricas; racismo.

\begin{abstract}
Identifying and interpreting racial discrimination practices is a complex issue. This text presents an analysis based on ethnographic field work with racialized migrants in the context of the Spanish city of Madrid. Specifically, it is an approach to the rhetorical forms which people have to explain that they have experienced and suffered racist discrimination practices. In this sense, beyond the spectacular practices of discrimination such as aggression or discursive offenses, I will observer more closely those accounts which speak about more ambiguous practices, more hidden; to see how they subjectively construct that what they perceive as objective.
\end{abstract}

Keywords: racial discrimination; racial embodiment; perception; rhetorics; racism.

\section{Introducción}

Hablar y escribir sobre las formas de racismo contemporáneo no es tarea fácil. Las lógicas de diferenciación, y sus expresiones en forma de prácticas de discriminación, han ido modificándose de tal manera que en la actualidad identificar e interpretar las prácticas de discriminación con motivo racial no es un

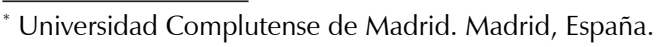


asunto que genere consenso alguno. Es más, el universo de las discriminaciones raciales contemporáneas, es un campo en el que existen muchos desacuerdos sobre lo que es interpretable como una práctica de discriminación racista y lo que no.

En ese sentido, me parece oportuno comenzar detallando cómo se han entendido y tratado algunos conceptos en el análisis y en la escritura del presente artículo. En primer lugar, aclarar que voy a hablar de persona racializada para referirme a aquellas personas sujetas a los procesos de racializacion ${ }^{1}$. Racialización como el proceso por el cual los individuos -y como consecuencia las colectividades- son construidos como diferentes en base a ciertos atributos. Dichas cualidades que se asignan, son aspectos que se señalan como diferenciales -respecto a los valores occidentales y blancos- y que pueden encarnarse en cuestiones fenotípicas, comportamentales, de valores o ideológicos, sociales, etc. No obstante, la característica que engloba a todas estas formas de apuntar la diferencia, es que se trata de aspectos construidos como culturalmente diferentes y se asignan como un atributo naturalizado, asociado y vinculado de la población a la que se apela, que se asume y construye como grupo racial. Por consiguiente, entiendo el racismo como el proceso en el que al tratar de "otro", se reifica y radicaliza a la vez su diferencia -que no necesariamente conlleva jerarquización-: donde reificar significa que existen rasgos que se definen como una esencia de la alteridad; y radicalizar supone una sobredeterminación de estos rasgos frente a cualquier otra forma posible de caracterización- (Fassin, Fassin, 2006).

Partiendo de estas definiciones no me parece pertinente distinguir entre racismo y xenofobia. Considero que además, en el contexto de campo realizado, hablar de xenofobia es un eufemismo (Stolcke, 2000). Supone omitir que las discriminaciones contemporáneas son mecanismos atravesados y sostenidos por padrones históricos de desigualdad social, es decir, que no sólo hablan de los procesos más actuales, sino que relatan también históricos conflictos de poder como el colonialismo (Ávila, Malo, 2010). Asimismo, modera la reflexión sobre las consecuencias paralelas que tuvo el giro del lenguaje de lo racial después de la Segunda Guerra Mundial; que si bien el propósito de la erradicación de la categoría "raza" era acabar con el carácter ideológico de las doctrinas y discriminaciones racistas, la sustitución de dicho término por otros contribuyó a

También, utilizo dicho término porque los propios movimientos sociales anti-racistas hablan desde esa categoría de "racializadas" para englobar y referirse a las personas que se identifican con atributos diferenciales -culturalmente hablando- a los que componen el imaginario occidental y que quieran hacer uso de ella. A dicha categoría se adscriben usualmente personas que se autoidentifican como afrodescendientes, gitanas, latinas, asiáticas, musulmanas, africanas, personas negras, etc. 
encubrir -y por tanto a descargar de contenido político- una problemática con implicaciones prácticas cotidianas para las personas entonces, y ahora.

Así, en el presente artículo pretendo exponer algunas de las formas narrativas que las personas tienen para explicar que han experimentado y sufrido prácticas de discriminación. Esto es, cómo éstas explican que han vivido un trato diferencial, en qué códigos lo han detectado, y cuando lo consideran discriminatorio hacia su persona, qué expresiones utilizan para dar objetividad a dicha práctica.

En ese sentido, más allá de las prácticas espectaculares de discriminación racista como agresiones $u$ ofensas explícitas, en el presente voy a detenerme en aquellos relatos que hablan de prácticas de discriminación más ambiguas, más encubiertas, aquellas que en muchas ocasiones son difíciles de detectar, como un gesto, una mirada, un suspiro, etc.; para ver cómo construyen subjetivamente aquello que perciben como objetivo.

En concreto, lo que expongo a continuación es un abreviado análisis derivado de los datos de campo ${ }^{2}$ recogidos en los últimos seis años en el encuentro con personas migrantes racializadas que residen en la ciudad de Madrid. El trabajo, de carácter etnográfico, se ha fundamentado principalmente en la realización de observación participante con dos movimientos sociales madrileños ${ }^{3}$ que en su discurso de base tienen la creencia de la existencia de un racismo institucional como práctica cotidiana, cuyas receptoras son las personas migrantes. Paralelamente, se han realizado un total de doce entrevistas

\footnotetext{
Trabajo de campo realizado en el marco de una Tesis Doctoral dirigida por la Doctora Adela Franzé Mudanó, dentro del Departamento de Antropología Social de la Universidad Complutense de Madrid. Profesora, guía y fiel compañera a la que agradezco por su continua insistencia para que desarrolle un trabajo riguroso con la antropología, y honesto con las personas.

3 El groso del trabajo de campo ha sido desarrollado principalmente en dos espacios activistas. El primer contacto con el campo fue en 2010 y se extendió por un periodo de cuatro años -desde 2010 hasta 2014- en uno de los colectivos que lucha contra el racismo policial e institucional en la ciudad de Madrid. Un año después, 2015, desarrollé una segunda fase de trabajo de campo que duró aproximadamente un año y medio, en otro colectivo de Madrid que lucha por los derechos humanos y la universalización de los derechos sociales. Al mismo tiempo, desarrollé junto con mi compañero y sociólogo Javier García Raboso -al cual aprovecho para también agradecer que siga compartiendo conmigo sus reflexiones, militancias y cuidados- un pequeño estudio en el año 2013, sobre la composición política del movimiento por el derecho a la vivienda en una de las asambleas de barrio, del cual salieron siete entrevistas. Realicé cinco entrevistas en profundidad a personas migrantes fuera del circuito activista, y a lo largo de estos años fui recogiendo conversaciones informales, situaciones y reflexiones con otras compañeras, que sin duda han engrosado y profundizado en la reflexión sobre el objeto de estudio de la tesis: los racismos cotidianos. Debido a la delicadeza del tema y fiel a la protección del anonimato de las personas en la cual se sustenta la disciplina antropológica, no se va a hacer mención de los nombres de dichos colectivos y se modificarán los datos significativos que pudieran revelar la identidad de las personas, como forma de guardar la confidencialidad y el respeto hacia las mismas.
} 
en profundidad, once de ellas a personas migrantes que no participaban en ninguno de estos dos espacios.

El análisis ha conjugado y articulado datos de diferente índole. Desde prácticas no discursivas a prácticas discursivas, la observación de la pura acción y del propio contexto en el que se gestan las conversaciones. Conversaciones tanto formales -esas que son guiadas, más estructuradas y reconocidas como entrevistas- como aquellas que emergen más espontáneas en el trascurso del campo. Entendiendo que en metodología cualitativa, la conversación informal tiende a ser en muchos casos una técnica privilegiada frente a la formal, ya que mediante un menor grado de directividad, consigue una aproximación al punto de vista de los sujetos lo más cercano posible a sus propios modos de hablar, manifestarse y de posicionarse en situaciones ordinarias de la vida cotidiana (Devillard, Franzé, Pazos, 2012).

Así, voy a comenzar mencionando algunos elementos socio-históricos y contextuales de las lógicas de diferenciación social, para situar el marco en el que las prácticas de discriminación racial se ubican, particularmente en la escena europea actual. Y entender las posibles consecuencias de éstos en las formas en cómo las prácticas de diferenciación se manifiestan, cómo se identifican, cuáles se señalan o cuáles son los códigos y contenido que legitiman la denuncia y reconocimiento de este tipo de hechos como racistas.

Con todo, ver qué retóricas aparecen y a qué elementos discursivos recurren las personas cuando manifiestan haber experimentado una discriminación, en un contexto en el que estas prácticas aparecen de manera ambigua, sutiles o enmascaradas.

\section{1. "Los otros" no siempre han sido los mismos. Breve recorrido histórico por las lógicas de diferenciación social}

La existencia de mecanismos de diferenciación de las poblaciones no son aspectos propios de las sociedades contemporáneas. Ciertamente, en todas las sociedades a lo largo de los tiempos se evidencian prácticas que diferencian al "otro". Sin embargo, las pautas y bases de la construcción del "otro" han ido mutando, estableciéndose de manera diversa y dando lugar a formas de discriminación variadas dependiendo del momento temporal y el lugar. Y es que "los otros" no siempre han sido los mismos.

En relación a la construcción de las razas y las ideas racistas, ha habido considerables investigadores e investigadoras que han señalado que frente al imaginario de raza asociada a la concepción puramente biológica, las jerarquías de poblaciones no han estado siempre ligadas a dicha idea (Van Dijk, 2003). Al contrario, datan la entrada de la Modernidad como el momento en el que comienzan a gestarse dichas concepciones. Es con la implantación del "racismo 
científico" durante esta época, mediante la cual se genera un giro significativo en el campo de las relaciones raciales. Se pasó entonces, de un modelo de diferenciación y distinción social ligado a argumentos puramente teológicos, a un pensamiento que sostenía que las diferencias morales, intelectuales y culturales tenían su raíz en una supuesta dotación biológica (Guillaumin, 1995).

Esta doctrina del "racismo científico" consistió en la introducción de ideas que, bajo la legitimidad de las ciencias, se centraron particularmente en la demostración e implantación científica de unas bases de naturalización de las diferencias entre poblaciones humanas, asentando así el concepto biológico de raza. Se trataba de la construcción de un razonamiento que, según Anthony Marx (1998), fue insertado por las élites blancas respaldándose en un discurso de legitimidad científica dando lugar a todo tipo de leyes y políticas que defendían, de una manera u otra, estas concepciones que abanderaban la supremacía blanca.

Como consecuencia, desde mediados del siglo XIX hasta finales del siglo XX, se erigieron a lo largo del planeta nuevos ordenes nacionales; ordenes que bajo fundamentos de naturaleza racial y desigualdad sociocultural establecían leyes y políticas que separaban jurídica y socialmente a poblaciones, que excluían, expulsaban o exterminaban a grupos a los que se suponía inferiores. Y es que estas teorías fueron desarrollándose sirviendo como respaldo de genocidios, holocaustos que enmascaraban relaciones de explotación, prejuicios de clase, intereses económicos, así como las relaciones de dominación colonial a lo largo de todo el mundo (Fassin, Fassin, 2006).

La concepción de la categoría "natural" de raza se mantuvo intacta durante décadas. No fue hasta después de la Segunda Guerra Mundial cuando desde Europa, aterrados por los efectos que ese pensamiento había desembocado, se empezaron a replantear el concepto y buscaron dar un giro en la ideología de lo racial. Estudiosos postcoloniales como Aimé Cesaire (2006), atribuyen ese impulso a la conmoción vivida a causa del exterminio nazi. Así, señala que mientras el horror había sido aceptado durante siglos en otras partes del planeta como en África o Asia, no estremeció al mundo hasta que se hizo en territorio local y hacia población blanca.

Fue también en el entorno de las élites científicas desde donde aparecieron los primeros consensos en relación a que la raza no era más que una construcción social que servía para justificar relaciones de poder y dominación (Omi, Winant, 1986), reafirmando a su vez que las manifestaciones de las diferencias biológicas que habían dado como resultado las denominadas razas, únicamente podrían ser interpretadas como cuestiones sociales (Dressler, 2005 Apud Fassin, 2011; Guimarães, 2003). 
En este ambiente se plantearon los primeros cuestionamientos sobre los efectos sociales que la palabra raza podría generar si se seguía utilizando dentro de la arena científica y fue entonces cuando comenzó todo un esfuerzo desde las ciencias por enterrar dicho término (Goldberg, 2006).

Paralelamente arrancó un impulso por la universalización de los Derechos Humanos. Aparecieron en la escena pública importantes actores que supondrán un giro en la concepción de las relaciones raciales y de las propias prácticas racistas. En Europa es el momento del auge de los movimientos pro-derechos humanos, políticas de igualdad, Organizaciones No Gubernamentales, etc. Así, con la existencia, la implicación política, insistencia y persistencia de organismos socio-políticos, el conjunto de medidas jurídicas, comisiones de derechos humanos, grupos políticos, etc.; comenzaron a acentuarse las sanciones sobre las prácticas de discriminación racial.

Todo ello, contribuyó a un cambio en la forma de pensar las relaciones raciales y el racismo en sí, trasladada hasta nuestros días. Mientras los formatos más visibles de discriminación racial eran sancionados y se caminaba hacia la anulación de las prácticas racistas, aparecían nuevas formas y mecanismos de discriminación.

\section{Características de los racismos contemporáneos: infinidad de formas de racializar y discriminar}

Comienza un nuevo periodo de comprensión y definición de la esfera racial y las discriminaciones. Ante un escenario que apuesta por instaurar un silencio racial y bajo la mirada de los derechos humanos; emergen prácticas de discriminación más sutiles, ambiguas, veladas, ocultas y encubiertas. Las prácticas racistas adquieren formatos más tenues o menos extremos. No es que éstas desaparezcan; sino que se modulan, se reformulan y se adaptan a las restricciones públicas, apareciendo bajo otras lógicas, prácticas y conceptos. Se da una modificación en la praxis, en el lenguaje de lo racial -se hace una apuesta específica de suplantar lo racial por lo "étnico" (Gonzalez Alcantud, 2011; Stolcke, 2000; Chebel D’Appollonia, 1998)-, en la identificación de lo que son las discriminaciones raciales, pero sobre todo $-y$ a causa de todos estos desplazamientos- se da una reconceptualización de lo que se entiende, interpreta e identifica con racismo.

La consecuencia de todo ello a la hora de identificar, señalar o denunciar prácticas racistas, es que al ser tan sutiles son difíciles de asociar, identificar y catalogar (Sayyid, 2017).

Ciertamente, en muchas ocasiones las prácticas que se consideran racistas son únicamente aquellas más clásicas; vinculadas a cuestiones más puramente de jerarquía biológica -como puede ser el asociar un tipo de fenotipo a 
capacidades intelectuales- ${ }^{4}$ o aquellas relacionadas con situaciones de extrema discriminación -como una agresión física a alguien que procesa cierto tipo de creencia religiosa-. Además, éstas, recurrentemente se tildan de residuales, se imaginan como excepcionales, o se vinculan a expresiones de círculos muy específicos ligados principalmente a la extrema derecha.

Y sin embargo muy al contrario, la discriminación racial representa un hecho objetivo que no necesariamente requiere intencionalidad; es decir, que está enraizada en el pensamiento social de tal manera que se da de forma involuntaria, se despliega en los contextos más ordinarios de la vida e implica a la sociedad como un todo (Fassin, 2011). Es así como, focalizando la atención únicamente en las prácticas más espectaculares o evidentes, se dejan de atender aquellas prácticas que no se manifiestan en formatos de violencia explícita o aquellas de corte más cultural; relegándolas a la invisibilidad y a la no identificación como prácticas racistas (Van Dijk, 2003).

En esta línea, los hermanos Fassin (2006) advierten que se ha dado una modificación en la forma de enunciación de las discriminaciones, que se suavizan o se formulan en otras claves, pero que continúa habiendo orden racial. Asimismo indican que ha habido una metamorfosis de las prácticas y sugieren tres formulaciones a través de las cuales aparece el racismo contemporáneo hoy en día.

Por un lado, hablan de la existencia de un "racismo racial"; que entienden que es una racionalización racista basada en el paradigma evolucionista del racismo -aquel que basándose en aseveraciones científicas y en ideas evolucionistas, genera una jerarquía de poblaciones como modo para justificar los prejuicios de clase, intereses económicos y relaciones de dominación y explotación-.

Por otro lado, apuntan que prevalece una cierta "racialización no racista", que supone la creencia de que, en efecto, hay diferencias biológicas entre los diferentes grupos de población. Y sin embargo, si bien esta idea asume un pensamiento racialista, no necesariamente se vincula con la idea de una jerarquización de dichas diferencias, simplemente clasifica la diferencias como naturales. Según estos autores, esta dimensión de sistematización de las diferencias, conlleva afrontar la "raza" en un sentido estrictamente biológico, pero a su vez burdamente fenotípico ya que la raza se reduce a las diferencias de color de piel entre uno y otros.

Por último, añaden la existencia de un "racismo sin razas". Esta dimensión del racismo implica la racialización de la diferencias culturales; es decir, se

\footnotetext{
${ }_{4}$ Si bien la representatividad de discursos que avalan este pensamiento es ínfimo, en ciertos círculos -principalmente de extrema derecha- siguen vigentes, combinándose a su vez con otros formatos más de señalamiento de diferencia cultural.
} 
desplaza la concepción de "naturalización biológica" a la "naturalización de las diferencias culturales". En este caso es la característica de "lo cultural" lo que se inserta en las formas de diferenciar y discriminar; asumiendo, asentando y naturalizando esa "diferencia cultural" como una característica propia de las personas $-y$ de los grupos- a las que se les atribuye ${ }^{5}$. Como ejemplo ponen la idea de cómo la "cuestión musulmana" ha sido construida como una cuestión de diferencia racial.

Verena Stolcke (2000) reafirma estas ideas apuntando que, en efecto, los planteamientos racistas se desplazan hacia una evocación ubicua de la cultura, y que estas formas de construir al "otro" se sostienen en argumentos que exaltan la identidad nacional y la paz social, que se suponen amenazadas con la llegada de personas con hábitos culturales diferentes.

Es así como, al darse este desplazamiento de la concepción más puramente biológica a la cultural, aparecen infinidad de "racializados", distintos modos de "racialización" y muchas más lógicas de diferenciación y discriminación. Y es que se hibridan las nuevas formas de la diferencia con las comprensiones más clásicas del racismo. Asistiendo así, a la conjugación de modelos más viejos de versiones del racismo y la aparición de nuevas formas; que si bien constituyen procesos distintos, son complementarios (Chebel D'Appollonia, 1998) y se dan de manera articulada.

\section{3. "Lo notas, lo sientes". La dificultad de poner palabras a las discriminaciones}

Todo este conjunto nebuloso de formas en las que se manifiestan las lógicas de discriminación racial, hace que sea realmente complejo medir, interpretar, señalar y denunciarlas. En este contexto en el que el mundo de las discriminaciones raciales es atravesado por diversos elementos, y muy en concreto por la forma ambigua y de carácter ambivalente en la cual se expresan las prácticas; la identificación y reconocimiento de dichas situaciones con la etiqueta "racista" resulta verdaderamente un reto.

Por un lado, este reto expone la falta de consenso social respecto al tema y revela ciertos conflictos de poder históricos y posicionamientos legítimos actuales existentes ante denuncias y señalamiento de situaciones discriminatorias. Por otro, advierte sobre los códigos y contenidos que son válidos y legítimos a la hora de justificar qué prácticas son consideradas racistas y cuáles no.

Más aún, ante el marco de una sociedad que requiere de sobrejustificación de hechos, datos objetivos, observables o cuantificables. Que a su vez desecha, con razonamientos sobre la subjetividad individual,

\footnotetext{
5 Se corresponde con la definición de racismo descrita en la primera página.
} 
la percepción personal o incluso la sensibilidad; argumentos de las personas que denuncian haber sufrido prácticas discriminatorias. Que desestima las narraciones sobre emociones, sensaciones y percepciones, como datos lícitos que puedan explicar situaciones. Es un desafío hablar o escribir sobre ello. Incluso para las propias personas que viven dichas circunstancias -las afectadas directas- hablar, señalar, describir y explicar en qué situaciones han experimentado racismo y por qué, resulta complejo. $Y$ es que en primera instancia, la combinación de la sutileza de las prácticas junto con el rechazo que la sociedad da a explicaciones subjetivas -que las rebaja a acusaciones sin argumentos o sin datos cuantificables o demostrables-, conlleva un no reconocimiento de dichas situaciones como objetivas. Todo ello, hace que estas personas se vean interpeladas a tratar de explicarse con otras y variadas fórmulas para que su discurso de denuncia resulte eficaz.

Ciertamente, en algunos acontecimientos de nuestra vida cotidiana y principalmente en el encuentro con otras personas, se dan confusiones. Hay situaciones que generan un desajuste en la comprensión de lo que vivenciamos, de la situación concreta que experimentamos y que da como resultado el no saber cómo enmarcar un comentario, un gesto, una mirada, etc. Este desencaje o confusión que se produce a la hora de interpretar algunos códigos, se presenta con relevancia en la vivencia de las discriminaciones raciales, por su carácter ambivalente.

Por otro lado, en otras muchas ocasiones las personas que sufren una discriminación saben el significado de esos hechos y tienen clara su interpretación; ya que tal y como refiere Didier Fassin (2011) la percepción de la discriminación racial, esté basada en hechos objetivos reconocidos o constituya un sentir "he sentido que me han discriminado", es una experiencia corporal profundamente incrustada -"racial embodiment"-. Y sin embargo, resulta un desafío encontrar palabras o hechos evidentes que resulten legítimos para una denuncia de una práctica que se manifiesta de forma velada, ante una persona que nunca ha vivido discriminación racial porque no forma parte de un grupo racializado -o de la particularidad por la que se racializa a ese grupo-.

En ese sentido, es interesante ver cómo en muchas ocasiones cuando las personas relatan una situación discriminatoria, apelan a un elemento discursivo común: el sentir o el notar un cuestionamiento hacia su persona. Esto es, para explicar, describir y justificar las situaciones que no son explícitas, es usual que recurran a lo largo de su relato a los sentimientos y emociones que experimentaron durante la escena concreta, como modo de validar la acusación de discriminación o racismo que enuncian. 
A continuación expongo algunos casos, que han sido seleccionados específicamente porque ilustran claramente esta cuestión.

Éste es un fragmento de la entrevista realizada a Vera, una mujer brasileña que en el momento en el que se recoge la conversación lleva ocho meses residiendo en España, en Madrid más específicamente. Recientemente tuvo un aborto involuntario y en esta conversa me narra cómo vivió ella su paso por la consulta ginecológica después de la hospitalización.

V- [...] Llegué al médico y ella [la ginecóloga] no me quería examinar. Me miró, me hizo unas preguntas, me preguntó si yo estaba intentando quedarme embarazada aún y tal. Y me atendió, súper seca. [...] Yo entré, ella me dio los buenos días normal y cuando abrí la boca y ella vio que yo no era española, sentí un tratamiento diferente por su parte. Y fue la primera vez que yo me sentí realmente discriminada, que yo sentí que fue por eso mismo, isabes? Que no era cosa de mi cabeza. [...] Yo nunca me imaginé en esa situación, estaba muy sensible aún por lo que había pasado. Y ella no me quería examinar y le dije que la otra doctora me había dicho que me tenía que hacer la prueba. Ella me respondió que allí la médica era ella y que ella sabría. Así, con esas mismas palabras, muy seca. Yo le pregunté si había algún lugar que yo pudiera hacerme la prueba, por lo privado, pagando. Porque yo no conozco nada, ¿no? Y ella...

L- Porque ella no te quería hacer la prueba...

V- Noooooo, no. Así que en el momento le pregunté si podía pagar para hacerme la prueba, porque yo estaba con eso en la cabeza, y con miedo dentro de mi de que algo pudiera estar mal. Y ella: "no, puedes tumbarte ahí, puedes, que te voy a hacer". Y fui, y la asistente de ella fue a preparar el aparato para hacer el ultrasonido intravaginal. Ella entró en la sala, no me dio... no me dio esa toalla que envuelve, me hizo quitarme la ropa allí, allí donde estábamos, no entré en el baño ni nada. Ella no se puso ni guantes, cogió el aparato y juro que no duró ni tres segundos. Lo introdujo y lo sacó. Y me dijo: "¿No te dije que estaba todo bien?". Sin guantes, con esas palabras. Y yo llorando, porque yo estaba muy sensible, y ella tratándome de aquella manera, ¿sabes? No tuve ni reacción para discutir con ella de lo mal que estaba aún. Y ella no se puso ni guante ni nada, lo puso, lo quitó y me dijo "ino te dije que estaba todo bien?". Ni me dio papel para que me limpiara... porque ellos [ginecólogos] te ponen un gel y se queda toda la parte húmeda. Nada, me puse la braga de la manera que estaba, la ropa y me manché todo el pantalón con el gel. Y salí...[...]

[Vera, mujer brasileña de 23 años. Madrid]

El relato de Vera es una descripción minuciosa de actos que pretenden evidenciar la experiencia de discriminación que ella ha sentido. Refiere en varias ocasiones al "yo sentí", al sentimiento que experimentó, justificando que no era una cosa inventada por ella, sino que a pesar de que esa sensación le resulte difícil de describir con palabras o incluso no existan palabras para definir 
esa percepción, ella analiza que fue porque ella no es leída como española debido a su acento.

Dentro del contexto de vulnerabilidad en el que ella se reconoce que estaba, por la reciente irrupción no deseada del embarazo y que como me cuenta, estaba llorando delante de la ginecóloga, explica con precisión los actos humillantes que vivió en la consulta, haciendo hincapié en gestos de precariedad y deshumanización en su atención. Vera me narra desde que entró en la sala de consulta cada movimiento de la doctora, especificando cómo se negaba a atenderla. Cuando ésta aceptó hacerle la revisión, Vera va detallando cada gesto y acto de la revisión: cómo la ginecóloga no le dio la toalla, cómo para la exploración no se puso guantes -resaltando este hecho en varias ocasiones durante la conversación-, indicando que no le dio papel para limpiarse y se marchó manchada, etc.

Todos estos elementos que Vera resalta sobre el desarrollo de la escena, responden a la forma de evidenciarme por qué ella se sintió discriminada en esa situación. Son los contenidos objetivos que explican ese sentir. Generalmente los sentimientos no se aceptan como "pruebas" objetivas de discriminación, tampoco para explicar ese cambio de actitud que la doctora tuvo con ella, y Vera lo sabe, por eso me relata cada movimiento del desarrollo de la consulta.

Ciertamente, es complejo evidenciar estas experiencias ya que no hay datos cuantificables, ni hechos extremos que las constaten, en ocasiones las personas no tienen ni palabras para describirlas. Simplemente las sienten.

Se trata de sentires y emociones incrustadas en el cuerpo. Un cuerpo que tiene unos marcos sociales de memoria -en relación a una experiencia pasada ya vivida o en relación a experiencias de otras personas o marcos de ideas construidas-, que se ponen en marcha en el momento que se vive una situación, por muy ambigua que ésta sea o duda que genere, se activa y le da sentido según lo aprendido y las interpretaciones hechas sobre experiencias vividas previamente. Estos marcos existen para con las relaciones sociales y las interdependencias entre las personas, son discursos de un cuerpo con una memoria sobre experiencias pasadas e interpretadas (Burkitt, 1999). En el caso de Vera, en este fragmento, refiere a nunca antes haber sufrido discriminación, sin embargo reconoce esos marcos de experiencia discriminatoria que otras personas migrantes le han relatado -tal y como me expone a lo largo de la conversación con ejemplos sobre sus amigas o historias que ha escuchado-. Incluso a lo largo de la entrevista expone en varias ocasiones a que ella no va al médico porque no tiene derecho ni siquiera a vivir en España, ya que está sin la situación regularizada. Con todo, se intuye que existe una memoria de experiencias - propias y ajenas- que le hace percibir e interpretar la situación de la consulta con la doctora en claves de discriminación. 
La siguiente conversación es con Mamadou, un chico senegalés de 27 años. El fragmento expresa muy bien estas ideas que aparecen también en el caso de Vera.

M- [...] Hay racismo en discoteca [...] A veces no te pueden negar la entrada porque tú eres más correcto que la gente que entra, pero ves que no están contentos de verte. No sé...

L- ¿Cómo lo percibes eso?

M- Natural... se ve, tú ves una chica que esta mirando, tú sabes que está interesada en ti, si ves que alguien... por la forma de mirarte sabes que esta persona no te quiere. [...] Llama más la atención cuando es negro.

L- ¿Por qué?

M- Porque es asíiiiiiiii. Porque es así, la gente tiene esta mentalidad, no cambia.

[...]

M- A veces a la gente no le gusta la cara, pero tú sientes que la gente lo está haciendo, está opinando.

L- ¿En dónde ves eso?

M- En todos los sitios dónde vas. A veces vas con, con una chica que es muy guapa y entras en la discoteca y la gente te mira. Bueno, los chicos ya vienen a hablar con tu chica, dicen "tú no la mereces". Y cuando las chicas ven esto, ellas quieren te cubrir pero "itú quien eres realmente? Tendrás algo especial para que estés con una chica tan guapa". [...] Por ejemplo hay gente que opina positivamente y gente que opina negativamente. A veces los chicos cuando ven eso tienen un poco celos.

L- ¿Por qué crees?

M- Porque, porque es así, porque lo ves en sus formas de ser, en sus formas de acercar[se] a tu chica.

L- Pero, ¿por qué crees que es la gente se extraña?

M- La gente se extraña porque... es un negro con una blanca y la gente no suele verlo siempre. [...] I Don ‘t know, no sé. No sé por qué pero ves que algo pasa, aunque la gente opine o no, pero están pensando algo. [...] Lo notas cómo la gente te mira y cómo la gente se acerca.

[Mamadou, hombre senegalés de 27 años. Actualmente residiendo en Senegal]

Cuando como antropóloga hago entrevistas, siempre planteo temas generales para ir ahondando en cuestiones más concretas. Si quiero que me hablen de experiencias de discriminación o de racismo, nunca lo hago en esos términos, simplemente espero a que las personas con las que converso aludan al tema. Lo interesante es que siempre sacan el tema. En el caso de Mamadou las discriminaciones raciales salen desde el comienzo, cuando me habla de cómo fue parado por la policía en el aeropuerto en su llegada a Madrid y expulsado en su primer intento de entrar en España. Hablamos de su vida durante más de 
dos horas: vivienda, ocio, trabajo, comida, amistades, parejas, etc. pero cada tema nos lleva al mismo punto, a narrarme el racismo que experimenta por ser un hombre negro africano residiendo en Madrid.

En estos pequeños fragmentos que he escogido de nuestra charla, se pueden vislumbrar algunas de las cuestiones y elementos retóricos que también aparecían en el relato de Vera. Así como ésta -y muchas otras personas que he entrevistado- indican haber vivido situaciones discriminatorias pero no utilizan la categoría "racismo" para catalogarlas, Mamadou lo hace rotundamente "hay racismo" y a continuación pone algún ejemplo vivido para constatarlo. Sin embargo, en todas las ocasiones cuando trata de explicarme por qué sabe que "no están contentos de verte", hace referencia a gestos, formas de acercarse, formas de ser de las personas, partiendo y avalándolas desde su interpretación subjetiva.

Describir emociones o sensaciones que uno percibe es complejo en este contexto de no reconocimiento de la sutileza. No existen palabras para ello por eso refiere a la percepción, a los sentimientos. Trata incluso de acercarme a su posición y sensaciones poniendo voz a esos gestos y miradas con palabras, cuando en realidad en esas interacciones que él me expone no hay habla. Sin embargo, él lee esos cuerpos y los interpreta. Más aún, él se sabe leído a través de las otras personas, lee qué imágenes sobre sí mismo se crean. Se interpreta a sí mismo a través de los otros, porque tiene una experiencia pasada que le hace interpretar esas cuestiones.

Ese cuestionamiento que él interpreta que hacen de su persona, ya lo dice él mismo en el fragmento, no siempre es entendido en términos negativos. También lee opiniones positivas -que en todo caso son también interpretados como cuestionamientos e interpretaciones que los demás hacen sobre él mismo-. Mamadou refiere a las relaciones afectivo-sexuales entre negros y blancas, pero tal y como me decía Amina, una mujer palestina de 45 años, el cuestionamiento sobre la vida de una persona migrante es continuo y todo el mundo se atreve a hacerlo.

A- Hay gente que te miran y te preguntan "¿estás feliz aquí?" i¿Qué significa estoy feliz aquí?! Estoy feliz dónde sea, no porque es España, tierra de Dios... [se ríe]. Bueno, te miran como... [se hace un silencio]. Pero bueno, lo entiendo, cada uno con su cultura, entiendo perfectamente cómo piensan... perfectamente nadie puede, yo no puedo decir perfectamente pero, yo creo que tengo la experiencia para entenderlo.

L- ¿Quién te dice estas cosas?

A- Eh... en situaciones personales con mis relaciones. Hay relaciones de todos los tipos. Hay relaciones con personas con mi círculo muy intimo que no tengo estas cosas, pero círculo así más alejado un poco. Y sí, te preguntan “iestás feliz? ¿qué haces aquí? Ya llevas 5 años, ¿ya cómo 
manejas la vida, ya te adaptas a la vida europea?" [se ríe] iYo qué sé qué es la vida europea o qué es esto! Es como te miran del tercer mundo, vamos, es esto al final: tú eres del tercer mundo... Pero para mi son tonterías, ellos te ponen, te están poniendo en un sitio superior que tú, que yo. Superior que yo ipor qué? Porque habéis nacido aquí, porque habéis tenido una vida siempre así, tenéis a lo mejor más dinero para vivir... para consumir, vamos. Y es súper... para mi es absurdo. No tengo cultura europea, no soy europea y sus definiciones, ellos lo inventan. Yo soy de otra cultura pero tampoco estoy cerrada, yo de cualquier cultura no cojo algo y estoy estricta de... no. Así, vivo mi vida tranquilamente con las cosas que me resultan positivas [...].

[Amina, mujer palestina de 45 años. Madrid]

Del relato de Amina se percibe cómo ella interpreta esos cuestionamientos que otras personas hacen sobre su vida desde que vive en España. Preguntas que ella interpreta y traduce en definiciones en la que la encajan, por ser mujer extranjera proveniente de un país musulmán. Posiciones en la que siente ser colocada, a través de cuestionamientos sobre su modo de vida, sobre su proceso de adaptación a un país europeo como España; que no son sino formas -muchas veces no intencionales- de señalar la diferencia cultural o el choque de los supuestos valores entre los occidentales y, en este caso los islámicos. Que a pesar de que Amina se autodefina como una persona atea, ella lee a través de los ojos de los demás, de las miradas, que la perciben, la definen y colocan como musulmana.

Por último recojo un pequeño fragmento de una charla con Maite, una mujer española blanca de 27 años. Maite señalaba justamente esta misma dimensión del sentir que las personas opinan y cuestionan. En una conversación informal hablando de su pareja actual, me cuenta que durante una época previa a conocerle salió con un chico negro y cómo fue sorprendida cuando en su entorno las personas cuestionaban y opinaban constantemente sobre su relación. Incluso cómo personas que no les conocían le hacían sentir a través de gestos o miradas, cuando iban juntos por la calle.

M- No sabría cómo describirlo... la gente opina. La gente opina siempre, en positivo y en negativo. O sea, vas a un restaurante un poco "así" [elegante] y te miran. Nadie dice nada pero te miran y es raro, como que no pegas con él, como "iqué hacen éstos juntos!", ¿no? Yo que siempre voy así, vestida y soy muy coqueta y claro me arreglo y más cuando iba con mi pareja por ahí, y él normal en vaqueros ino?... Pero luego, también tienes el lado opuesto, que paseas de la mano por Lavapiés, por ejemplo me acuerdo un día, y una persona que no te conoce de nada te sonríe como "aiiii mira qué monos, una pareja interracial". Yo que sé... es que nadie dice nada pero con la mirada opinan. Y es que estas cosas no las había vivido con otras parejas. Parejas blancas, claro.

[Maite, mujer española no racializada de 27 años. Madrid] 
En este relato de Maite, también se hace una referencia al elemento del sentir para avalar la existencia de esas miradas o gestos casi imperceptibles, que ella interpreta como interpelaciones hacia su relación. Maite, al igual que hace Mamadou, trata de dar objetividad a esas emociones poniendo discurso a las miradas. Reafirma ese sentir, aludiendo a una comparación experiencial en relación a otras parejas que tuvo con anterioridad, pero no sólo. Esta interpretación del sentirse interpelada por las miradas, se nutre a su vez por los marcos de experiencia de otras personas cercanas: los relatos de vivencias de discriminación de otros o hechos que ella misma ha visto e interpretado en esas claves. Más aún, estas situaciones adquieren sentido y se interpretan también, por su vinculación a entornos de activismo anti-racista que le hacen interpretar esas circunstancias en claves de discriminación.

\section{Conclusiones}

Con el presente artículo he querido traer a discusión y reflexión algunos aspectos con los que me he topado durante mi inmersión en el campo de las relaciones raciales y las discriminaciones en el contexto español.

Profundizar en las retóricas de las personas que expresan haber experimentado discriminaciones por cuestión racial; por un lado, me lleva a explorar la variedad de formas que toman las lógicas de discriminación en la actualidad, ahondar en las características de los racismos contemporáneos y a indagar cómo éstos se ponen en juego en la vida cotidiana. Por otro lado, me aproxima a la complejidad de la que se compone el campo de señalamiento y denuncia de las discriminaciones raciales, así como a captar las flujos de las fuerzas de poder y legitimidad del mismo.

En ese sentido, como he mostrado mediante una pequeña muestra de datos, las personas para explicar subjetivamente aquellos hechos que han percibido como objetivamente discriminatorios, recurren al elemento de la percepción o del sentir. Y es que ante prácticas que se manifiestan casi imperceptibles y difícilmente interpretables debido a su poca explicitud o evidencia práctica, describir con palabras esas miradas, gestos, reacciones corporales o cambios de actitud que han suscitado ese sentimiento de discriminación, resulta complejo. No obstante, las personas señalan "sentir cosas" ante esas prácticas nimias - pequeñas en cuanto a visibilidad, no por las consecuencias que éstas traen- que leen de los cuerpos. Prácticas corporales a las que incluso en ocasiones se les añaden discursos, que no son sino las interpretaciones de dichas miradas, gestos, etc. convertidas en habla.

Son frente a estas interpretaciones por los que los cuerpos de las personas reaccionan con las sensaciones. Al final, las emociones son disposiciones incrustadas e incorporadas en la memoria de experiencias de los cuerpos, 
que saltan cuando se experimenta una situación y se interpreta poniendo en relación con la memoria de acontecimientos pasados -vividos por una misma o por otros-. Ese sentir, que en ocasiones no se le pueden atribuir palabras para definirlo, se activa en el momento, se acciona en el momento en el que el cuerpo lo rememora o lo vincula a experiencias pasadas. Ese trasvase experiencial puede llevar a situaciones concretas, a imágenes, escenas, personas, o simplemente a una emoción positiva o negativa que no se consigue asociar a nada en concreto. La característica de ambivalencia por la que las discriminaciones raciales contemporáneas están atravesadas, hacen que expresar el haber sentido algo, sea realmente complejo.

Lo que estos relatos revelan es que son los cuerpos los que están en medio de la práctica, que aparece sutil y muda, pero que ésta genera consecuencias. Precisamente la reacción de la persona receptora que experimenta e interpreta la práctica en base a marcos sociales vividos, reconocidos y ya interpretados.

El cuerpo se torna el eje central de toda la experiencia racial. Y sin embargo, esa complejidad para señalar por qué una persona se ha sentido discriminada, dice "lo he sentido" o "lo he percibido", sin conseguir describir con más detalle, o sin poder cuantificar o demostrar con palabras; hace que en ocasiones se debilite su veracidad o la legitimidad que exige la sociedad cuando se hace una acusación de racismo. Precisamente por la dificultad de trasladar la complejidad y las sensaciones del mundo de las discriminaciones raciales, a palabras.

\section{Bibliografía}

ÁVILA, Débora; MALO, Marta. Manos invisibles. De la lógica neoliberal en lo social. Trabajo Social Hoy, n. 59, p. 137-171, 2010.

BURKITT, Ian. Bodies of Thought. Embodiment, identity \& Modernity. London: SAGE Publications, 1999.

CÉSAIRE, Aimé. Discurso sobre el colonialismo. Madrid: Akal, 2006.

CHEBEL D'APPOLLONIA, Ariane. Los racismos cotidianos. Barcelona: Bellaterra Editorial, 1998.

DEVILLARD, Marie José; FRANZÉ, Adela; PAZOS, Álvaro. Apuntes metodológicos sobre la conversación en el trabajo etnográfico. Política y Sociedad, v. 49, n. 2, p. 353-369, 2012.

FASSIN, Didier. Racialization. How to do Races with Bodies. In: MASCIA-LEES, Frances (ed.). A Companion to the Anthropology of the Body and Embodiment. UK: Wiley-Blackweel, 2011, p. 419-434.

FASSIN, Didier; FASSIN, Éric. De la question sociale à la question raciale? Représenter la société française. Paris: La Découverte, 2006.

GOLDBERG, David T. Racial Europeanization. Ethnic and Racial Studies, v. 29, n. 2, p. 331-364, 2006. 
GONZALEZ ALCANTUD, José A. Racismo elegante: de la teoría de razas culturales a la invisibilidad del racismo cotidiano. Barcelona: Bellaterra, 2011.

GUIMARÃES, Antonio Sérgio. Como Trabalhar com "raça" em sociologia. Educação e Pesquisa, n. 29, p. 93-107, 2003.

GUILLAUMIN, Colette. The Specific Characteristics of Racist Ideology. In: IDEM. Racism, Sexism, Power and Ideology. London: Routledge, 1995, p. 29-60.

MARX, Anthony. Making Race and Nation: A Comparison of South Africa, the United States and Brazil. Cambridge: Cambridge University Press, 1998.

OMI, Michael; WINANT, Howard. Racial formation in the United States: from the 1960s to the 1980s. New York: Routledge \& Kegan Paul, 1986.

PAGER, Devah. Medir a discriminação. Tempo Social, Revista de sociologia da USP, v. 18, n. 2, p. 65-88, 2006.

SAYYID, Salam. Post-Racial Paradoxes: rethinking European racism and anti-racism. Patterns of Prejudice, v. 51, n.1, p. 9-25, 2017.

STOLCKE, Verena. ¿Es el sexo para el género lo que la raza para la etnicidad...y la naturaleza para la sociedad?. Política y Cultura, Universidad Autónoma Metropolitana Unidad Xochimilco, Distrito Federal, México, n. 14, p. 25-60, 2000.

VAN DIJK, Teun A. Racismo y discursos de las élites. Barcelona: Gedisa Editorial, 2003.

Recibido para publicación en 15.04.2018

Aceptado para publicación en 25.06.2018

Received for publication in April 15 th 2018

Accepted for publication in June $25^{\text {th }}, 2018$

ISSN impresso 1980-8585

ISSN eletrônico 2237-9843

http://dx.doi.org/10.1590/1980-85852503880005305 